(2) Open Access Full Text Article

REVIEW

\title{
Inpatient charges and mental illness: Findings from the Nationwide Inpatient Sample 1999-2007
}

This article was published in the following Dove Press journal:

ClinicoEconomics and Outcomes Research

7 October 2010

Number of times this article has been viewed

\author{
Jim E Banta' \\ Ivorie Belk' \\ Kedon Newton' \\ Abdullah Sherzai ${ }^{2}$ \\ 'Department of Health Policy and \\ Management, ${ }^{2}$ Memory and Aging \\ Center, Department of Neurology, \\ Loma Linda University School of \\ Medicine, Loma Linda, CA, USA
}

Correspondence: Jim E Banta Department of Health Policy and Management, Loma Linda University School of Public Health, 2495I North Circle Drive, Loma Linda, CA 92350, USA Tel + I 9095587753

Fax + I 9095580469

Email jbanta@llu.edu

\begin{abstract}
Inpatient costs related to mental illness are substantial, though declining as a percentage of overall mental health treatment costs. The public sector has become increasingly involved in funding and providing mental health services. Nationwide Inpatient Sample data for the years 1999-2007 were used to: 1) examine Medicare, Medicaid, and private insurance charges related to mental illness hospitalizations, including trends over time; and 2) examine trends in mental comorbidity with physical illness and its effect on charges. There were an estimated 12.4 million mental illness discharges during the 9-year period, with Medicare being the primary payer for 4.3 million discharges, Medicaid for 3.3 million, private insurance for 3.2 million, and 1.6 million for all other payers. Mean inflation-adjusted charges per hospitalization were US\$17,528, US\$15,651, US\$10,539, and US\$11,663, respectively. Charges to public sources increased for schizophrenia and dementia-related discharges, with little private/public change noted for mood disorders. Comorbid mood disorders increased dramatically from 1.5 million discharges in 1999 to 3.4 million discharges in 2007. Comorbid illness was noted in $14.0 \%$ of the 342 million inpatient discharges during the study period and was associated with increased charges for some medical conditions and decreased charges for other medical conditions.
\end{abstract}

Keywords: hospital charges, comorbidity, mood disorders, dementia, schizophrenia

\section{Background}

Societal costs for mental illness and substance abuse within the United States during 1992 were an estimated US\$370 billion, ${ }^{1}$ including indirect costs such as travel and waiting time and the support of family members. Homelessness is common among patients with serious mental illness, ${ }^{2}$ and an estimated $7 \%$ of those with serious and persistent mental illness are incarcerated in jail or prison each year. ${ }^{3}$ A "displacement model" has been proposed to account for the fact that a group of people seem to cycle between the criminal justice system, the welfare system, and the mental health system. ${ }^{4}$

Direct mental health treatment costs include services at hospitals, federally funded community mental health centers, residential treatment centers for emotionally disturbed children, institutional care, community-based services, and prevention services. ${ }^{5}$ In 2001, expenditures for such mental health and substance abuse services, including medications, totaled US\$85.4 billion, which was $6.2 \%$ of all health care spending. ${ }^{6}$ Mental health and substance abuse treatment costs are expected to increase to US\$239 billion by 2014 but continue to fall as a share of all health spending. ${ }^{7}$ 


\section{Cost-shifting}

One area of economic interest is cost-shifting, which is formally defined as "one agency reducing its own expenditures by inducing another agency to pay for similar services" ${ }^{8}$ For example, an earlier study found a greater rate of psychiatric services by veterans at Department of Veterans Affairs facilities in areas with reduced per capita funding for state and county mental health hospitals". ${ }^{9}$ Another study found limited evidence that Medicaid beneficiaries with a mental illness were more likely to be jailed after a managed care program was implemented. ${ }^{8}$ Two major pathways of managed care resulting in more jail use have been proposed: unmet mental health need may result in greater illicit drug use or increased nondrug related charges, particularly misdemeanors such as dining-and-dashing. ${ }^{10}$ Cost-shifting or even differences in care based on funding source may be subtle and perhaps even unintentional. For example, a study of veterans with heart failure found that those enrolled in managed care Medicare were more likely to receive recommended drug therapies than veterans enrolled in fee-for-service Medicare. ${ }^{11}$

A related topic is potential increased medical costs due to mental illness. Patients with mental illness and an ambulatory care sensitive medical condition are more likely to be hospitalized, and to have a longer length of stay and higher costs. ${ }^{12}$ Likewise, homeless individuals with serious mental illness are more likely to use inpatient and emergency services rather than outpatient mental services. ${ }^{2}$ Some mental disorders frequently coexist with other medical disorders, such as depression and cardiovascular disease, particularly congestive heart failure. ${ }^{13}$ The risk of developing diabetes mellitus is $2-3$ times higher in patients with schizophrenia compared with those not having schizophrenia, perhaps mediated by psychiatric medications. ${ }^{14}$ There are also associations with conditions, such as rheumatoid arthritis ${ }^{15}$ and chronic pulmonary illness. ${ }^{16}$ Studies have shown increased risk of hospitalization, longer lengths of stay, and higher costs among those diagnosed with depression and diabetes mellitus ${ }^{17}$ and congestive heart failure. ${ }^{18}$ There are at least three mechanisms proposed as to how mental illness may result in worse outcomes from medical illness: poor lifestyle practices, direct internal biological influences of mental illness, and substandard interaction with the medical care system. ${ }^{19}$

\section{Inpatient mental health costs and funding} Inpatient care is still the single most expensive type of mental health service; however, its relative share of expenditures has been declining. In 2001 , hospitals accounted for $27 \%$ of mental health expenditures ( $16 \%$ of expenditures for general hospitals and $11 \%$ for specialty hospitals). ${ }^{6}$ Public sources funded $63 \%$ of those mental health expenditures (27\% from Medicaid, $23 \%$ from other state and local funding, $8 \%$ from Medicare, and $5 \%$ from all other federal sources including the Department of Veterans Affairs), and 37\% of funding for mental health services came from all private sources ( $22 \%$ private insurance, $13 \%$ out of pocket, $2 \%$ all other private sources). ${ }^{6}$

A number of factors are responsible for the declining overall percentage of inpatient to total mental health treatment costs. There has been a dramatic reduction in the number of psychiatric beds, from 524,878 in 1970 to 211,199 in $2002 .{ }^{20}$ Much of that decrease has come from state mental hospitals, which accounted for $27 \%$ of all psychiatric beds in 2002, compared with almost $80 \%$ of psychiatric beds in $1970 .{ }^{20}$ Psychiatric treatment advances including new prescription drugs, partial hospitalization, residential facilities, and other treatment philosophy changes have reduced the demand for psychiatric hospitalization. ${ }^{21}$ However, because cost-containing initiatives for inpatient services have forced clinicians to develop a model that reserves such services for more severe, acute cases ${ }^{22}$ costs continue to increase among those who are hospitalized.

It has been suggested that Medicaid funding has allowed states to spend more on total mental health care, especially care outside the purview of state mental health agencies. ${ }^{23}$ However, federal Medicaid policies may have worsened mental health treatment for indigent persons with severe mental illness, ${ }^{24}$ primarily due to funding restrictions on state mental hospitals. ${ }^{25}$ It does appear that as many states and counties shift more of their mental health budgets onto Medicaid, there are fewer funds to provide services for lowincome, uninsured people with serious mental illness, who are not eligible for Medicaid. ${ }^{26}$ One consequence is that a majority of emergency department directors within California believe that limited mental health treatment resources for uninsured persons is a significant factor in increased emergency room visits related to suicide attempts. ${ }^{27}$ Other research in California has shown regional differences in the percentage of indigent psychiatric hospitalizations, which may be reflective of variations in public funding for outpatient care. ${ }^{28}$

Although Medicare funds a relatively small portion of total mental health expenses, its caps on reimbursement for psychiatric hospitalizations and different reimbursement policies for nondementia care, depending on the type of facility, has led to significant changes in patient care and length of stay. ${ }^{22}$ Medicare funds freestanding psychiatric hospitals, certified psychiatric units in short-stay general 
hospitals, and general hospital beds (scatterbeds). Between 1992 and 2002, general hospital beds received about half the reimbursement given to psychiatric units and long-stay hospitals;22 but a new prospective payment system was implemented in 2005. ${ }^{29}$

Managed care, which aims to decrease medical expenditures including inpatient care, emerged in the 1980s. Today, most private insurance-funded behavioral health care in the United States is reimbursed by managed behavioral health care organizations, which have achieved sizable decreases in behavioral inpatient care spending by reducing payments, admissions, and length-of-stay. ${ }^{21}$ Analysis of hospitalization data from 1988 to 1997 found that psychiatric length of stay decreased more rapidly than other conditions, particularly among the privately insured. The more rapid decline in length of stay for mental health and substance abuse stays than for all stays may have been a result of greater incentive for cost containment and therefore more intensive care management and advances in treatment technology, especially medication. ${ }^{30}$

\section{Study purpose}

It is commonly expected that public sources will fund an increasingly larger percentage of mental health costs, with private insurance paying for less. ${ }^{7}$ This descriptive study uses nationwide hospitalization data between 1999 and 2007 to examine changes in the relative amount of funding sources for inpatient mental health treatment, with a particular interest in stratifying by the most common diagnoses. A second objective is to examine mental health comorbidity among patients not hospitalized for a psychiatric condition, to examine trends over time and to see whether comorbidity is associated with higher total charges.

Better understanding of the true costs and funding related to mental illness is critical for improving treatment, particularly because those with mental illness are often involved in multiple treatment/service systems and often have physical illnesses. Individual organizations may reduce their costs by withholding care; but this may result in higher societal costs.

\section{Methods}

\section{Data}

The Nationwide Inpatient Sample (NIS) is the largest allpayer inpatient care database in the United States. ${ }^{31}$ It is one of a family of datasets developed as part of the Healthcare Cost and Utilization Project (HCUP), a Federal-State-Industry partnership sponsored by the Agency for Healthcare Research and Quality. NIS approximates a 20\% stratified sample of US community hospitals, with the sampling frame covering about
$90 \%$ of all hospital discharges in the United States. ${ }^{31}$ This dataset has been used for previous mental health research, such as evaluating hospitalization trends among children and adolescents ${ }^{32}$ and interaction of mental illness among those hospitalized with HIV infection. ${ }^{33}$

Two analytic files were developed for this analysis. The first consisted of all NIS discharges between 1999 and 2007 having a primary diagnosis indicating mental illness. That sample file consisted of 2,534,232 records, representative of 12.46 million discharges. The second file for comorbidity analysis was a combination of all discharges during the 9 years, with dummy variables indicating the presence of comorbid mental illness; that is, a mental illness diagnosis in diagnosis variables 2 through 15 . That file comprised 70,052,217 records, representative of 341.92 million discharges.

\section{Mental health measures}

Mental illness was defined using single-level Clinical Classification Software (CCS) codes developed as part of HCUP. This classification codes thousands of individual International Classification of Diseases, 9th revision, clinical modification (ICD-9-CM) codes into fewer than 300 unique categories, ${ }^{34}$ and a CCS code is provided for each of the 15 diagnosis fields within the NIS data. That system was updated in 2007 to include more detailed mental health and substance abuse categories. The CCS codes in the analytic files were updated using an SAS program downloaded from the HCUP website. ${ }^{35}$ Categories used to define mental illness were: mood disorders (CCS 657), schizophrenia and other psychotic disorders (CCS 659), delirium, dementia, and amnestic and other cognitive disorders (CCS 653), and "other mental illness" which included adjustment disorders (CCS 650), anxiety disorders (CCS 651), attention-deficit, conduct and disruptive behavior disorders (CCS 652), developmental disorders (CCS 654), disorders usually diagnosed in infancy, childhood, or adolescence (CCS 655), impulse control disorders and NEC (CCS 656), and personality disorders (CCS 658). Preliminary analysis suggested that CCS coding were not reliable for trends of alcohol and substance abuse even after using the "cross-walk" SAS program.

\section{Analysis}

The data file consisting of primary mental diagnoses was examined looking at basic demographics (age, gender, and race), hospital characteristics (bed size and location/teaching status), and type of mental illness, stratified by primary payer (Medicare, Medicaid, private insurance including HMO, and all other payers - self-pay, no charge, and other). Significance 
testing was conducted using the Rao-Scott chi-square test (a design-adjusted version of the Pearson chi-square) for categorical variables. Hospital charges were adjusted for inflation to 2007 values using the consumer price index (CPI) for all urban consumers, using $1982-1984$ as a baseline of $100 .{ }^{36} \mathrm{As}$ an example, 1999 dollars were converted to CPI-adjusted 2007 dollars by first multiplying charges by the 2007 annual average of 207.342 and then dividing by the 1999 annual average of 166.6. We estimated the total number of discharges for each year for the four different types of mental illness and then annual charges by payer type within those mental illness categories.

Comorbidity in the larger data file was first examined by estimating the annual number of discharges having each of the four groups of mental illness. Then overall mental comorbidity was examined stratified by major diagnostic category (MDC), a system which assigns a discharge to one of 25 (plus a leftover) categories of illness type/body system based on primary (ICD-9-CM) diagnosis. We looked at overall prevalence of comorbid mental illness and mean charges. As a follow-up, we looked at age and number of diagnoses on the discharge record by specific mental comorbidity among a handful of MDCs. File manipulation and survey-adjusted statistical analyses ${ }^{37}$ were conducted using SAS 9.2 (SAS Institute, Cary, NC).

\section{Results}

Table 1 shows that between 1999 and 2007, there were an estimated 4.31 million discharges covered primarily by Medicare, 3.27 million by Medicaid, 3.23 million by private insurance, and 1.60 million by all other sources. Medicare hospitalizations had the highest average charges, the longest length of stay, and the highest average age (60.2 versus mid-30s for all other conditions). Medicaid discharges had the lowest average age and were more likely to be Black or Hispanic (note that some states do not allow HCUP to release race data). They were also most likely to be seen in

Table I Nationwide Inpatient Sample discharges with a primary diagnosis of mental illness (1999-2007)

\begin{tabular}{|c|c|c|c|c|}
\hline & $\begin{array}{l}\text { Medicare } \\
4.31 \text { million }\end{array}$ & $\begin{array}{l}\text { Medicaid } \\
3.27 \text { million }\end{array}$ & $\begin{array}{l}\text { Private insurance } \\
3.23 \text { million }\end{array}$ & $\begin{array}{l}\text { All other payers } \\
1.60 \text { million }\end{array}$ \\
\hline \multirow[t]{2}{*}{ Charges, mean (std error) } & 17,528 & $|5,65|$ & 10,539 & 11,663 \\
\hline & $(330)$ & $(658)$ & $(255)$ & $(450)$ \\
\hline Length of stay & $5.5(0.08)$ & $5.4(0.19)$ & $4.7(0.10)$ & $4.2(0.18)$ \\
\hline Age & $60.2(0.30)$ & $34.3(0.30)$ & $36.2(0.26)$ & $35.6(0.20)$ \\
\hline Female (pct) & 54.3 & 53.2 & 58.7 & 45.4 \\
\hline \multicolumn{5}{|l|}{ Race } \\
\hline White & 57.1 & 38.7 & 56.3 & 49.7 \\
\hline Black & 11.1 & 20.2 & 7.7 & 15.5 \\
\hline Hispanic & 4.4 & 9.0 & 4.0 & 7.2 \\
\hline Asian or Pacific Islander & 0.6 & 1.0 & 1.0 & 1.2 \\
\hline Native American & 0.2 & 0.3 & 0.2 & 0.5 \\
\hline Other & 1.6 & 2.9 & 1.9 & 2.9 \\
\hline Missing data & 25.0 & 27.8 & 28.8 & 23.0 \\
\hline Mood disorders & 39.4 & 52.2 & 72.6 & 62.5 \\
\hline Schizophrenia and other psychotic disorders & 32.9 & 35.3 & 12.4 & 22.0 \\
\hline Delirium, dementia, and other cognitive disorders & 23.3 & 1.2 & 3.1 & 2.4 \\
\hline Other mental illness & 4.4 & 11.2 & 12.0 & 13.1 \\
\hline \multicolumn{5}{|l|}{ Hospital control } \\
\hline Government, nonfederal & 11.8 & 14.8 & 8.2 & 22.5 \\
\hline Private, nonprofit & 69.9 & 70.4 & 78.1 & 63.1 \\
\hline Private, investor-owned & 16.2 & 12.9 & 12.0 & 12.3 \\
\hline Missing & 2.1 & 1.9 & 1.8 & 2.1 \\
\hline \multicolumn{5}{|l|}{ Hospital bed size } \\
\hline Small & II.I & 8.3 & 8.4 & 7.4 \\
\hline Medium & 26.9 & 28.4 & 23.5 & 26.6 \\
\hline Large & 62.0 & 63.3 & 68.1 & 66.0 \\
\hline \multicolumn{5}{|l|}{ Hospital status } \\
\hline Rural & 14.2 & 10.5 & 9.8 & 13.3 \\
\hline Urban, nonteaching & 45.1 & 40.7 & 44.4 & 42.2 \\
\hline Urban, teaching & 40.6 & 48.8 & 45.8 & 44.4 \\
\hline
\end{tabular}

Note: All comparisons significant at $P<0.00$ I level. 
urban teaching hospitals. Private insurance discharges were most likely to be female $(58.7 \%)$ and to be seen in large hospitals. Local government hospitals were most likely to treat "all other mental illness", while for-profit hospitals most likely to have Medicare discharges. Nearly three-fourths of private insurance discharges had mood disorders, compared with $52.2 \%$ for Medicaid and 39.4\% for Medicare. Nearly one-fourth of Medicare discharges were for dementia and delirium and roughly one-third of both Medicare and Medicaid discharges were for schizophrenia and other psychotic disorders.

Figure 1 shows that the annual number of psychiatric discharges has remained relatively constant between 1997 and 2007, particularly for delirium and other mental conditions, which each ranged between 112,000 and 146,000 annual discharges. There were between 713,000 and 800,000 mood disorder discharges and between 342,000 and 419,000 annual discharges for schizophrenia and other psychotic disorders.

Figures 2A through 2D also show relatively stable trends, with CPI-adjusted charges generally being consistent with the overall percentages presented in Table 1. Figure 2A shows that even though the majority of private insurance discharges are for mood disorders, Medicare is actually charged the most for mood disorders due to greater volume, roughly US\$4 billion a year since 2003. Mood disorder charges for all other payer sources (excluding Medicare, Medicaid, and private insurance) nearly doubled from US\$1 billion in 2005 to US\$2 billion in 2007. Figure 2B reveals a similar trend in that Medicare is charged more for schizophrenia and other psychotic discharges than is Medicaid. Figure 2C shows that Medicare charges for dementia and delirium have increased from US\$1.4 billion in 1999 to US\$2.2 billion in 2007, and Figure 2D shows that Medicaid is clearly charged the most for discharges having other mental illness diagnoses.

Trends in comorbid mental illness are shown in Figure 3. Mood disorders have clearly grown in prevalence, increasing from being noted as comorbid in 1.5 million discharges in 1999 to 3.4 million discharges in 2007. There have also been steady, but not nearly so dramatic, increases in comorbidity of the other three conditions.

Table 2 examines all discharges between 1999 and 2007, grouped by MDCs. Among all discharges, a comorbid mental diagnosis was noted in $14.0 \%$ of discharges, with mean charges of hospitalizations having mental comorbidity of US\$21,925 and mean charges among those with no mental comorbidity of US\$21,593. Of the 26 MDC categories, mental comorbidity was associated with higher charges in 10 categories, lower charges in 11 categories, and roughly equivalent charges in five categories. Excluding mental and substance-related conditions, a comorbid mental illness was most commonly noted among discharges related to the endocrine, nutritional and metabolic system $(21.2 \%$ of 10.8 million discharges) and respiratory system (20.1\% of 33.49 million discharges).

Table 3 examines a handful of MDCs in greater detail. One can see that there is variation in age and average charges depending on the specific type of comorbid mental illness. For example, among respiratory system discharges, comorbid schizophrenia and other psychotic disorders are clearly associated with higher charges (29,982 versus 24,796), and comorbid dementia and delirium is associated with higher charges among those with female reproductive system discharges $(24,373$ versus 16,799$)$.

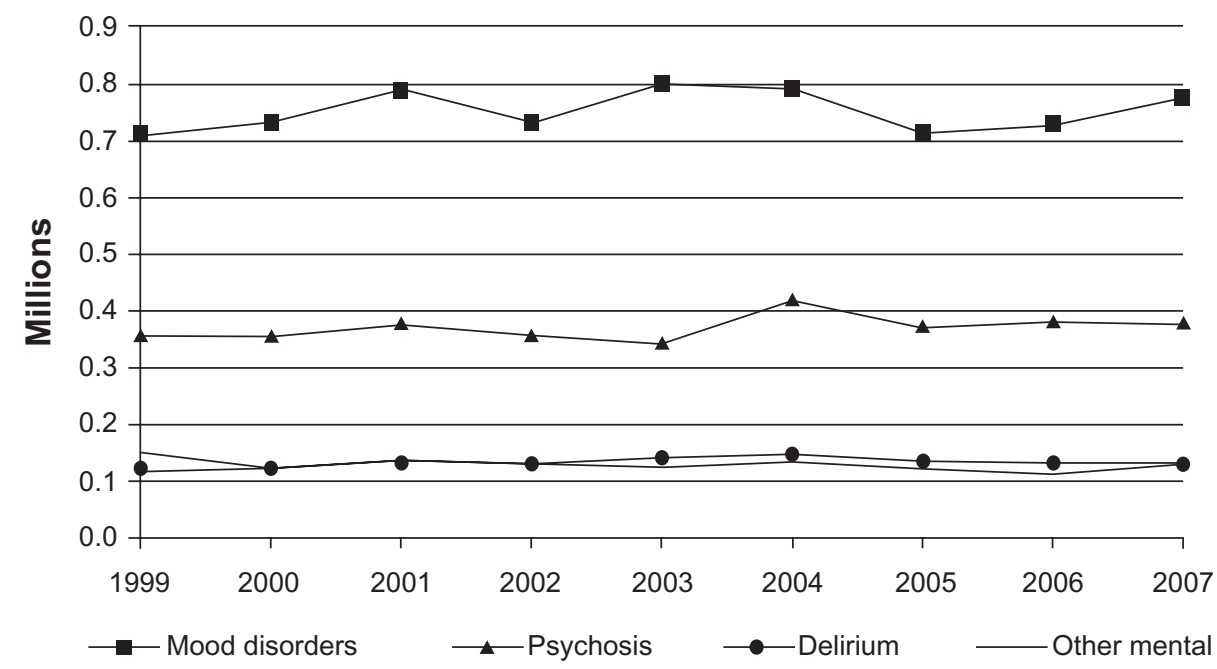

Figure I Nationwide Inpatient Sample, estimated number of annual discharges having a primary diagnosis of mental illness. 


\section{Discussion}

We found that the number of psychiatric discharges remained fairly stable between 1999 and 2007. Although charges to Medicare have increased, charges to private insurance have not decreased. It does not appear in aggregate that private insurance is shifting more of the financial burden to the public sector. On the other hand, it does appear in 2006 and 2007 that Medicaid charges for schizophrenia and other psychotic disorders decreased while similar charges to Medicare increased. However, with these crude data we are not able to truly study cost-shifting.

Although Medicaid is the predominant funding source for overall mental care, Medicare is charged more for psychiatric hospitalizations, even for those with a primary diagnosis of schizophrenia and other psychotic disorders. Medicare is clearly the main funding source for dementia and delirium. Furthermore, although individuals 80 years of age and greater comprise $5 \%$ of the US population, in 2004 they accounted for nearly $21 \%$ of all hospital stays which were related with mental health or substance abuse. ${ }^{38}$ However, it is noteworthy that the average age of Medicare discharges for mental illness was less than 65 years. This is consistent with other research that has found that psychiatric hospitalization among under-65 years of age, disabled, Medicare-funded beneficiaries, where reason for disability is mental problems, has increased steadily since the mid1980s. ${ }^{29}$ Although the rate of psychiatric hospitalization is low, an increased number of covered individuals (aging

A

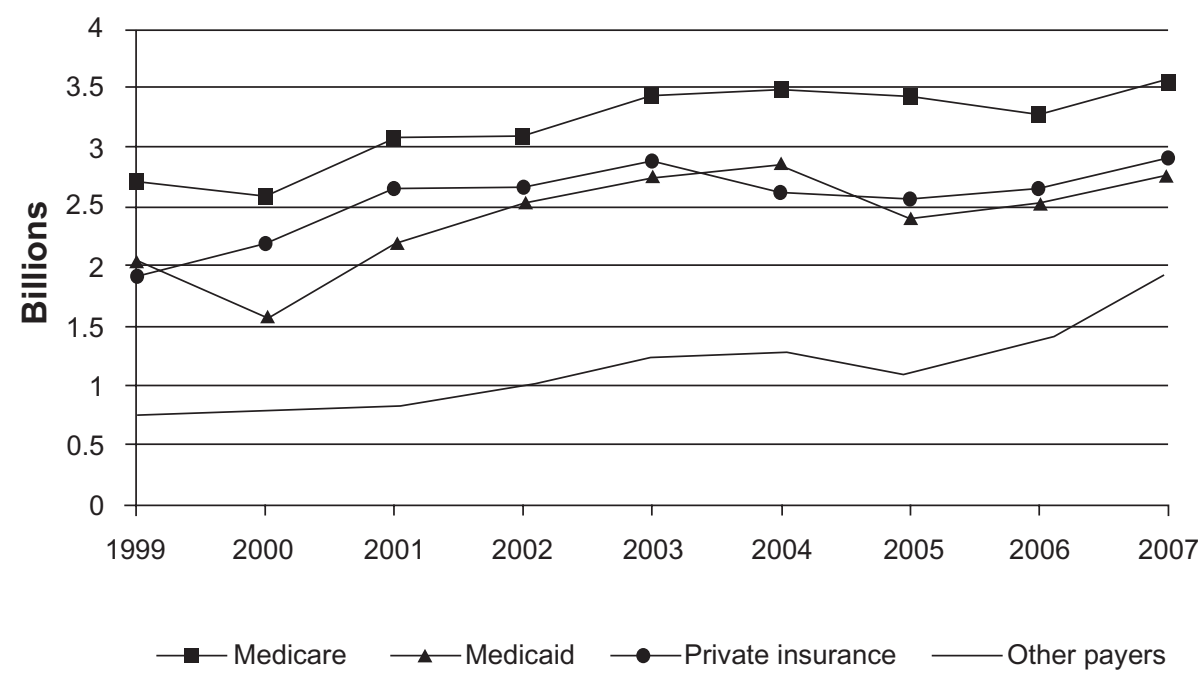

B

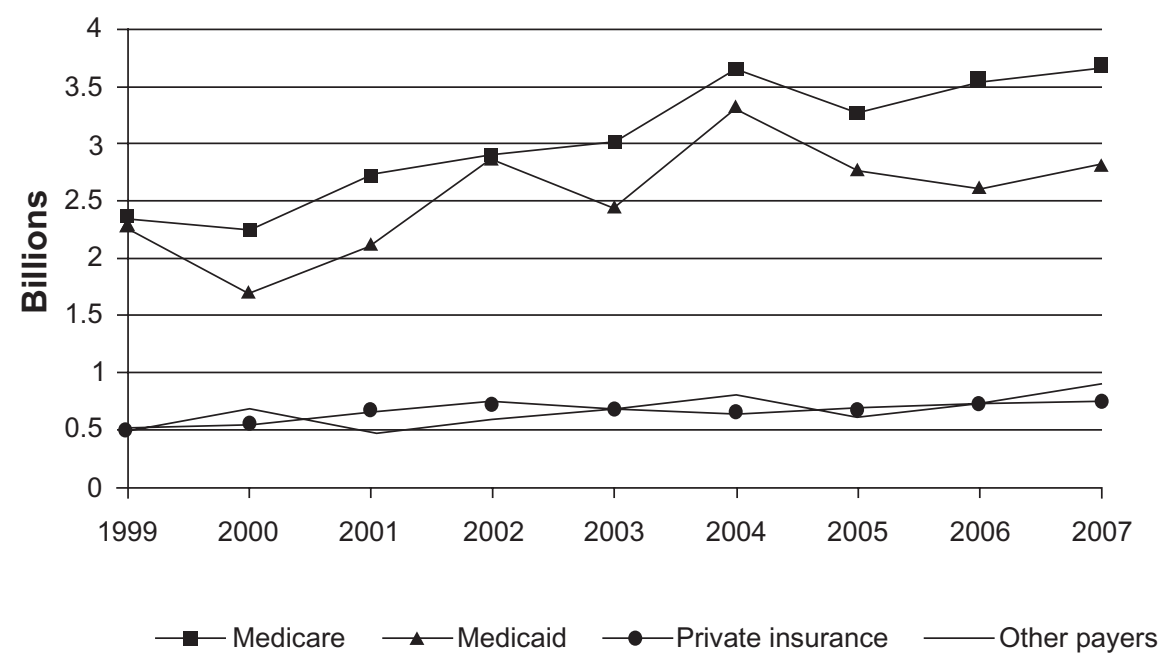

(Continued) 
C

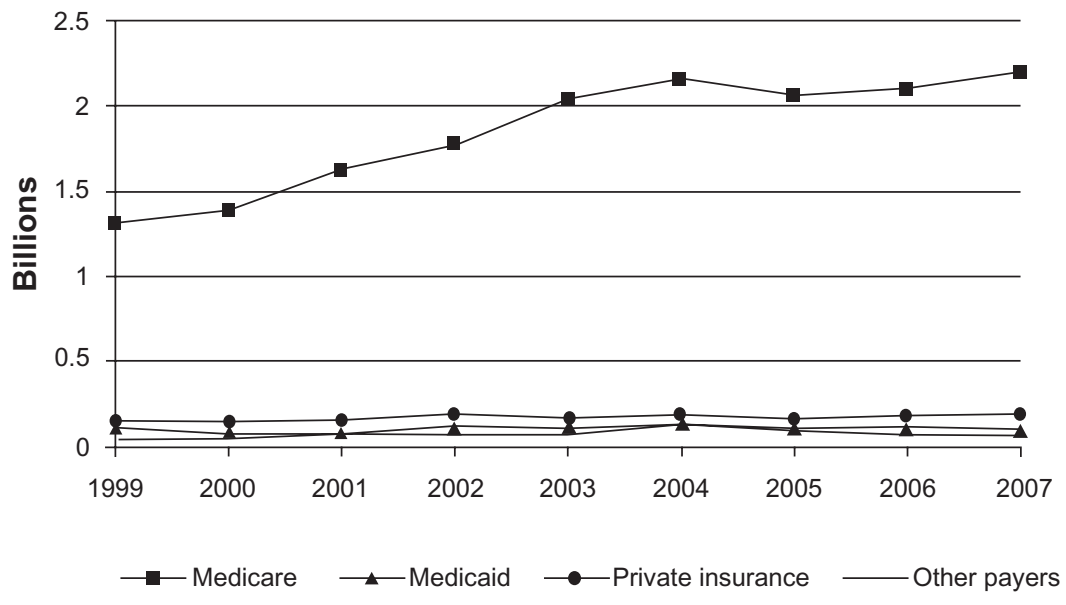

D

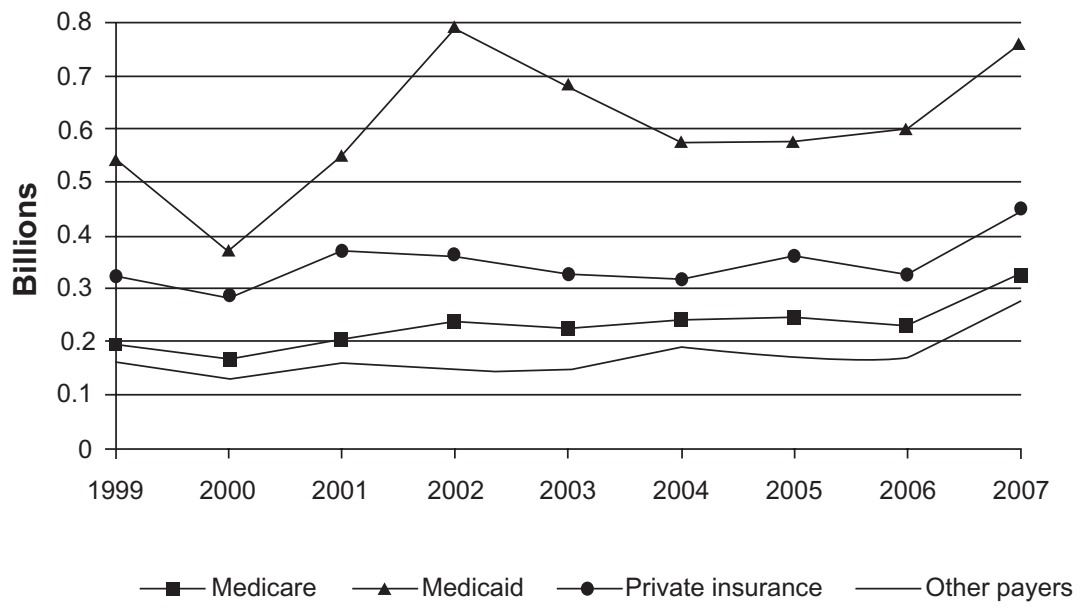

Figure 2 A) Nationwide Inpatient Sample estimated total annual charges by payer for discharges having primary diagnosis of mood disorders. Charges adjusted to 2007 dollars using consumer price index (CPI). B) Nationwide Inpatient Sample estimated total annual CPI-adjusted charges by payer for discharges having primary diagnosis of schizophrenia and other psychotic disorders. C) Nationwide Inpatient Sample estimated total annual CPI-adjusted charges by payer for discharges having primary diagnosis of delirium, dementia, and amnestic and other cognitive disorders. D) Nationwide Inpatient Sample estimated total annual CPI-adjusted charges by payer for discharges having primary diagnosis of other mental illness.

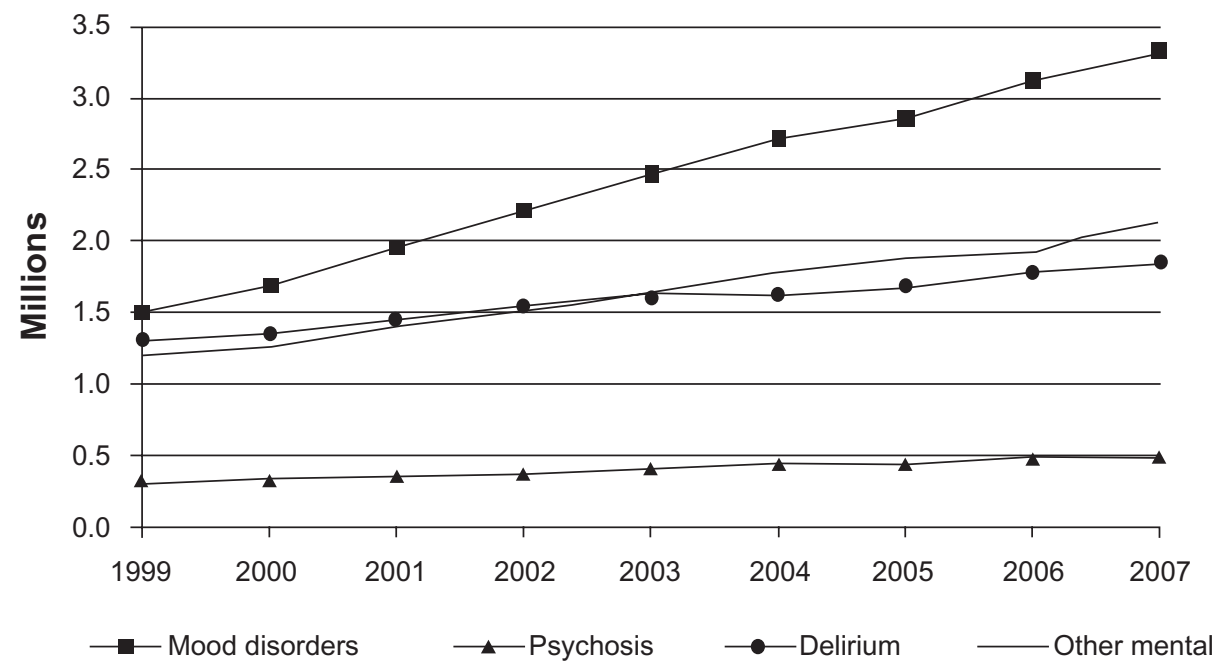

Figure 3 Among all Nationwide Inpatient Sample discharges, those with comorbid mental illness. 
Table 2 Nationwide Inpatient Sample discharges, 1999-2007. Major diagnostic categories (MDC) by comorbid mental illness

\begin{tabular}{|c|c|c|c|c|}
\hline MDC & $\begin{array}{l}\text { Estimate total } \\
\text { discharge (million) }\end{array}$ & $\begin{array}{l}\text { Comorbid mental } \\
\text { diagnosis (pct) }\end{array}$ & $\begin{array}{l}\text { Mean charges, }{ }^{a} \text { no } \\
\text { comorbid mental }\end{array}$ & $\begin{array}{l}\text { Mean charges, }{ }^{\text {a }} \text { comorbid } \\
\text { mental }\end{array}$ \\
\hline Pre-MDC & 0.11 & 3.7 & 19,803 & 17,596 \\
\hline Nervous system & 18.86 & 22.9 & 28,039 & 22,416 \\
\hline Eye & 0.52 & 10.2 & 15,822 & 17,167 \\
\hline Ear, nose, mouth and throat & 3.77 & 10.2 & 16,028 & 18,038 \\
\hline Respiratory system & 33.49 & 20.1 & 24,796 & 24,005 \\
\hline Circulatory system & 56.33 & 13.9 & 32,360 & 23,788 \\
\hline Digestive system & 29.49 & 14.3 & 23,524 & 21,784 \\
\hline Hepatobiliary system and pancreas & 9.32 & 11.8 & 28,498 & 26,439 \\
\hline $\begin{array}{l}\text { Musculoskeletal system and connective } \\
\text { tissue }\end{array}$ & 26.68 & I5.I & 30,513 & 30,643 \\
\hline Skin, subcutaneous tissue and breast & 7.65 & 15.0 & 17,489 & 19,452 \\
\hline $\begin{array}{l}\text { Endocrine, nutritional and metabolic } \\
\text { system }\end{array}$ & 10.80 & 21.2 & 17,322 & 17,323 \\
\hline Kidney and urinary tract & 12.08 & 18.5 & 22,644 & $|9,94|$ \\
\hline Male reproductive system & 2.02 & 7.1 & 18,703 & 19,903 \\
\hline Female reproductive system & 8.47 & 7.2 & 16,799 & 18,337 \\
\hline Pregnancy, childbirth and puerperium & 41.96 & 1.9 & 9,325 & 11,123 \\
\hline $\begin{array}{l}\text { Newborn and other neonates (perinatal } \\
\text { period) }\end{array}$ & 38.84 & 0.0 & 7,946 & 48,280 \\
\hline $\begin{array}{l}\text { Blood and blood forming organs and } \\
\text { immunological disorders }\end{array}$ & 3.68 & 12.2 & 21,387 & 21,410 \\
\hline $\begin{array}{l}\text { Myeloproliferative DDs (poorly } \\
\text { differentiated neoplasms) }\end{array}$ & 3.01 & 9.5 & $4 I, 564$ & 48,921 \\
\hline Infectious and parasitic DDs & 6.94 & 17.2 & 36,888 & 31,156 \\
\hline Mental diseases and disorders & 12.11 & 45.0 & 14,807 & 14,504 \\
\hline $\begin{array}{l}\text { Alcohol/drug use or induced mental } \\
\text { disorders }\end{array}$ & 3.93 & 40.5 & 10,407 & 10,024 \\
\hline Injuries, poison, and toxic effect of drugs & 4.52 & 33.8 & 21,697 & 14,742 \\
\hline Burns & 0.27 & 9.9 & 42,975 & 52,580 \\
\hline Factors influencing health status & 5.58 & 23.1 & 23,568 & 26,626 \\
\hline Multiple significant trauma & 0.66 & 8.6 & 75,977 & 66,429 \\
\hline Human immunodeficiency virus infection & 0.85 & 17.3 & $4|, 44|$ & 38,379 \\
\hline Total & 341.92 & 14.0 & 21,593 & 21,925 \\
\hline
\end{tabular}

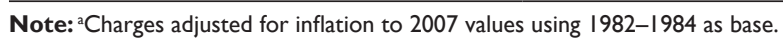

workforce, and broadening of standards) has resulted in more usage and greater costs. ${ }^{29}$

Inpatient mental illness comorbidity, particularly mood disorders, is increasing. There is mixed evidence regarding overall financial effect of comorbid mental illness on the CPI-adjusted charges of all MDC discharges. However, a review of a handful of MDCs clearly showed that some of the specific mental illnesses are associated with higher charges for some of the MDCs. The true effects of mental illness, particularly depression, are probably understated because psychiatric illness is under-detected in the elderly and hospitalized medical patients. ${ }^{17}$ Furthermore, results from the Aging, Demographics, and Memory Study suggests that 14\% of Americans aged 71 years and over have dementia, with prevalence nearly doubling every 5 years after age 70 (5\% of those aged $71-79$ to $37.4 \%$ of those aged 90 and older). ${ }^{39}$ The overall effect of comorbid mental illness on costs may also be understated by the fact of premature death; that is, public mental health patients die as many as 25 years younger than others in the general population. ${ }^{40}$

\section{Limitations}

This analysis is based on sampled records from discharge data which hospitals have submitted to their State's health agency, and which the State has submitted to the federal government. There of course could be errors in the data; but this data series has been extensively checked and the data used in multiple publications. We are limited to discharges, which is appropriate because the focus is on charges. However, on a clinical level, a more useful level of analysis denominator might be individuals, because roughly $40 \%$ of psychiatric inpatients are readmitted within a year of discharge. ${ }^{41}$ As a de-identified inpatient discharge dataset, it is not possible to link with other utilization data, such as outpatient care and medications, 
Table 3 Nationwide Inpatient Sample discharges, 1999-2007. Selected major diagnostic categories (MDCs)

\begin{tabular}{|c|c|c|c|c|}
\hline MDC & Estimated discharges & Mean charges & Age & Number of diagnoses \\
\hline \multicolumn{5}{|l|}{ Respiratory system } \\
\hline No mental comorbidity & $26,748,317$ & 24,796 & 55.2 & 6.4 \\
\hline Comorbid mood disorders & $2,787,982$ & 22,770 & 63.9 & 8.8 \\
\hline Comorbid schizophrenia/psychotic disorder & 519,380 & 29,982 & 64.0 & 8.7 \\
\hline Comorbid dementia/delirium & $2,426,938$ & 24,504 & 82.3 & 9.1 \\
\hline Comorbid other mental illness & 381,018 & 23,255 & 58.7 & 8.3 \\
\hline \multicolumn{5}{|l|}{ Endocrine, nutritional, and metabolic systems } \\
\hline No mental comorbidity & $8,511,632$ & 17,322 & 50.4 & 6.1 \\
\hline Comorbid mood disorders & $\mathrm{I}, 088,202$ & $18,0 \mid 4$ & 57.0 & 8.4 \\
\hline Comorbid schizophrenia/psychotic disorder & 224,932 & 17,245 & 60.8 & 8.0 \\
\hline Comorbid dementia/delirium & 840,686 & 16,648 & 81.5 & 8.8 \\
\hline Comorbid other mental illness & 450,120 & 16,215 & 51.0 & 8.0 \\
\hline \multicolumn{5}{|l|}{ Female reproductive system } \\
\hline No mental comorbidity & $7,862,637$ & 16,799 & 46.5 & 4.6 \\
\hline Comorbid mood disorders & 410,963 & 17,600 & 46.8 & 7.0 \\
\hline Comorbid schizophrenia/psychotic disorder & 21,545 & 16,897 & 46.6 & 4.8 \\
\hline Comorbid dementia/delirium & 39,384 & 24,373 & 79.9 & 8.7 \\
\hline Comorbid other mental illness & 37,533 & 18,383 & 46.8 & 7.0 \\
\hline \multicolumn{5}{|l|}{$\begin{array}{l}\text { Myeloproliferative DDs (poorly differentiated } \\
\text { neoplasms) }\end{array}$} \\
\hline No mental comorbidity & $2,722,809$ & 41,564 & 52.0 & 5.9 \\
\hline Comorbid mood disorders & $|5|, 29 \mid$ & 49,331 & 56.4 & 8.4 \\
\hline Comorbid schizophrenia/psychotic disorder & 20,111 & 45,623 & 61.6 & 8.6 \\
\hline Comorbid dementia/delirium & 46,879 & 36,903 & 78.2 & 9.3 \\
\hline Comorbid other mental illness & 18,337 & 55,267 & 49.0 & 8.1 \\
\hline
\end{tabular}

or to other programs such as social security, housing/income maintenance, or the criminal justice system. This dataset also does not include information from the Department of Veterans Affairs, which is the single largest provider of public mental health care in the United States, ${ }^{9}$ with as many as one-third of veterans receiving medical care also having a psychiatric diagnosis. ${ }^{42}$ However, this study includes the majority of treated mental health patients and includes all Medicare, Medicaid, and private insurance-funded discharges at community-based acute hospitals. This analysis presented overall number of discharges and charges, and did not adjust for individual characteristics such as age or comorbid medical conditions or for hospital-based characteristics. We also focused on charges rather than converting to costs. ${ }^{38}$

\section{Summary}

Total Medicare charges are greater than Medicaid charges for hospitalizations having a primary diagnosis of mood disorders, schizophrenia and other psychotic disorders, and dementia and delirium. Although the number of psychiatric discharges has remained fairly constant between 1999 and 2007, Medicare charges have trended upwards, and private insurance charges have remained constant. The prevalence of comorbid mood disorders in hospital discharges more than doubled during that time period, and there is evidence that this comorbid mental illness is associated with increased hospital charges.

\section{Disclosure}

The authors report no conflicts of interest in this work.

\section{References}

1. Fellin P. Chapter 6. Financing of mental health services. Mental Health and Mental Illness: Policies, Programs, and Services. Itasca, IL: FE Peacock Publisher, Inc; 1996:101-116.

2. Folsom DP, Hawthorne W, Lindamer L, et al. Prevalence and risk factors for homelessness and utilization of mental health services among 10,340 patients with serious mental illness in a large public mental health system. Am J Psychiatry. 2005;162(2):370-376.

3. Glied SA, Frank RG. Better but not best: recent trends in the well-being of the mentally ill. Health Aff (Millwood). 2009;28(3):637-648.

4. Wolch J, Philo C. From distributions of deviance to definitions of difference: past and future mental health geographics. Health Place. 2000;6:137-157.

5. Fellin P. Chapter 4. History of mental health programs, services and service delivery. Mental Health and Mental Illness: Policies, Programs, and Services. Itasca, IL: FE Peacock Publisher, Inc; 1996:55-72.

6. Substance Abuse and Mental Health Services Administration. National Expenditures for Mental Health Services and Substance Abuse Treatment 1991-2001: Mental Health Services Expenditures, 2001. Available from: http://www.samhsa.gov/spendingestimates/chapter3.aspx. 2009 Accessed 2010 Feb 15.

7. Levit KR, Kassed CA, Coffey RM, et al. Future funding for mental health and substance abuse: increasing burdens for the public sector. Health Aff (Millwood). 2008;27(6):w513-w522.

8. Domino ME, Norton EC, Morrissey JP, Thakur N. Cost shifting to jails after a change to managed mental health care. Health Serv Res. 2004; 39(5):1379-1401. 
9. Rosenheck R, Stolar M. Access to public mental health services: determinants of population coverage. Med Care. 1998;36(4):503-512.

10. Norton EC, Yoon J, Domino ME, Morrissey JP. Transitions between the public mental health system and jail for persons with severe mental illness: a Markov analysis. Health Econ. 2006;15(7):719-733.

11. Johnson ML, Petersen LA, Sundaravaradan R, et al. The association of Medicare drug coverage with use of evidence-based medications in the Veterans Health Administration. Ann Pharmacother. 2009;43(10):1565-1575.

12. Li Y, Glance LG, Cai X, Mukamel DB. Mental illness and hospitalization for ambulatory care sensitive medical conditions. Med Care. 2008; 46(12):1249-1256.

13. York KM, Hassan M, Sheps DS. Psychobiology of depression/distress in congestive heart failure. Heart Failure Review. 2009;14:35-40.

14. Okumura Y, Ito H, Kobayashi M, Mayahara K, Matsumoto Y, Hirakawa J. Prevalence of diabetes and antipsychotic prescription patterns in patients with schizophrenia: a nationwide retrospective cohort study. Schizophr Res. 2010;119(1-3):145-152.

15. Gettings L. Psychological well-being in rheumatoid arthritis: a review of the literature. Musculoskeletal Care. 2010;8(2):99-106.

16. Jong B, Oud M. Somatic diseases in patients with schizophrenia in general practice: their prevalence and health care. BMC Fam Pract. 2009;10(32).

17. Unutzer J, Schoenbaum M, Katon WJ, et al. Healthcare costs associated with depression in medically ill fee-for-service medicare participants. J Am Geriatr Soc. 2009;57(3):506-510.

18. Sayers SL, Hanrahan N, Kutney A, Clarke SP, Reis BF, Riegel B. Psychiatric comorbidity and greater hospitalization risk, longer length of stay, and higher hospitalization costs in older adults with heart failure. J Am Geriatr Soc. 2007;55(10):1585-1591.

19. Banta JE, Andersen RM, Young AS, Kominski G, Cunningham WE. Psychiatric comorbidity and mortality among veterans hospitalized for congestive heart failure. Mil Med. 2010. In press.

20. Substance Abuse and Mental Health Services Administration. Highlights of Organized Mental Health Services in 2002 and Major National and State Trends. Available from: http://mentalhealth.samhsa.gov/publications/ allpubs/sma06-4195/chapter19.asp. 2010. Accessed 2010 Feb 23.

21. Hoover DR, Akincigil A, Prince JD, et al. Medicare inpatient treatment for elderly non-dementia psychiatric illnesses 1992-2002; length of stay and expenditures by facility type. Adm Policy Ment Health. 2008;35(4):231-240.

22. Akincigil A, Crystal S, Hoover D, Kalay E, Prince J, Walkup J. Medicare Inpatient treatment for elderly non-dementia Psychiatric illness 1992-2002; length of stay and expenditures by facility type. Springer Science and Business Media. 2008;59(9):1046-1048.

23. Frank RG, Glied S. Changes in mental health financing since 1971: implications for policymakers and patients. Health Aff (Millwood). 2006;25(3):601-613.

24. Davoli JI. No room at the inn: how the federal Medicaid program created inequities in psychiatric hospital access for the indigent mentally ill. Am J Law Med. 2003;29(2-3):159-183.

25. Buck JA. Medicaid, health care financing trends, and the future of state-based public mental health services. Psychiatr Serv. 2003;54(7):969-975.

26. Cunningham P, McKenzie K, Taylor EF. The struggle to provide community-based care to low-income people with serious mental illnesses. Health Aff (Millwood). 2006;25(3):694-705.

ClinicoEconomics and Outcomes Research

\section{Publish your work in this journal}

ClinicoEconomics \& Outcomes Research is an international, peerreviewed open-access journal focusing on Health Technology Assessment, Pharmacoeconomics and Outcomes Research in the areas of diagnosis, medical devices, and clinical, surgical and pharmacological intervention. The economic impact of health policy and health systems
27. Baraff LJ, Janowicz N, Asarnow JR. Survey of California emergency departments about practices for management of suicidal patients and resources available for their care. Ann Emerg Med. 2006;48(4):452-458, 458.e1-e2.

28. Banta JE, Wiafe S, Soret S, Holzer C. A spatial needs assessment of indigent acute psychiatric discharges in California. J Behav Health Serv Res. 2008;35(2):179-194.

29. Cotterill PG. Medicare psychiatric admissions, 1987-2004: does the past offer insights for the future? Health Affairs. 2008;27(4):1132-1139.

30. Bao Y, Sturm R. How do trends for behavioral health inpatient care differ from medical inpatient care in US community hospitals? J Ment Health Policy Econ. 2001;4(2):55-64.

31. Agency for Healthcare Research and Quality. HCUP Databases: Healthcare Cost and Utilization Project (HCUP). Aug 2009. Available from: http:// www.hcup-us.ahrq.gov/nisoverview.jsp. Accessed 2010 Mar 15.

32. Case BG, Olfson M, Marcus SC, Siegel C. Trends in the inpatient mental health treatment of children and adolescents in US community hospitals between 1990 and 2000. Arch Gen Psychiatry. 2007;64(1):89-96.

33. Bansil P, Jamieson DJ, Posner SF, Kourtis AP. Trends in hospitalizations with psychiatric diagnoses among HIV-infected women in the USA, 1994-2004. AIDS Care. 2009;21(11):1432-1438.

34. Agency for Healthcare Research and Quality, Healthcare Utilization Project (HCUP). Clinical Classification Software (CCS) Single Level ICD-9-CM Codes. Available from: http://www.hcup-us.ahrq.gov/ toolssoftware/ccs/appendixasingledx.txt. 2009. Accessed 2010 Mar 5.

35. Agency for Healthcare Research and Quality, Healthcare Utilization Project (HCUP). Mental Health and Substance Abuse Clinical Classifications Software (CCS-MHSA). http://www.hcup-us.ahrq.gov/ toolssoftware/mhsa/mhsa.jsp. 2010. Accessed 2010 Jul 20.

36. Bureau of Labor Statistics. Consumer Price Index for all urban consumers (CPI-U) [updated 2010 May 19]. Available from: ftp://ftp.bls.gov/ pub/special.requests/cpi/cpiai.txt. Accessed 2010 Mar 28.

37. Houchens R, Elixhauser A. Final Report on Calculating Nationwide Inpatient Sample (NIS) Variances, 2001. HCUP Methods Series Report \#2003-2. Available from: http://www.hcup-us.ahrq.gov/reports/ calculatingnisvariances200106092005.pdf. US Agency for Healthcare Research and Quality; 2005 Jun. Accessed 2010 Feb 24.

38. Owens P, Myers M, Elixhauser A, Brach C. HCUP Fact Book No. 10. Care of Adults With Mental Health and Substance Abuse Disorders in US. Community Hospitals, 2004. AHRQ Publication No. 07-0008. ISBN 1-58763-229-2: Agency for Healthcare Research and Quality; 2007.

39. Plassman BL, Langa KM, Fisher GG, et al. Prevalence of dementia in the United States: the aging, demographics, and memory study. Neuroepidemiology. 2007;29(1-2):125-132.

40. Colton CW, Manderscheid RW. Congruencies in increased mortality rates, years of potential life lost, and causes of death among public mental health clients in eight states. Prev Chronic Dis. 2006;3(2):A42.

41. Thompson E, Neighbors H, Munday C, Trierweiler S. Length of stay, referral to aftercare, and rehospitalization among psychiatric inpatients. Psychiatr Serv. 2003;55(2):1271-1276.

42. Kominski G, Andersen R, Bastani R, et al. UPBEAT: the impact of a psychogeriatric intervention in VA medical centers. Unified Psychogeriatric Biopsychosocial Evaluation and Treatment. Med Care. 2001;39(5):500-512.

organization also constitute important areas of coverage. The manuscript management system is completely online and includes a very quick and fair peer-review system, which is all easy to use. Visit http://www.dovepress.com/testimonials.php to read real quotes from published authors. 